\title{
CMA position against separate regulations for medical cannabis draws ire and insults
}

\author{
- Cite as: CMAJ 2018 May 7;190:E574-5. doi: 10.1503/cmaj.109-5594
}

Posted on cmajnews.com on Apr. 17, 2018.

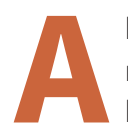
bad-tempered exchange at a medical-cannabis conference has highlighted a strong disagreement between the Canadian Medical Association (CMA) and some of its members on how medical cannabis should be regulated when the drug becomes legal.

Dr. Jeff Blackmer, CMA's vice-president of medical professionalism, was at the Canadian Consortium for the Investigation of Cannabinoids conference in Toronto to present the CMA's position. But the hostile response and personal attacks from the crowd led to him leaving before the session was over. "It was clear there was not going to be any reasoned debate or conversation," said Blackmer.
Dr. Mark Ware, a cannabinoid researcher at McGill University and executive director of the consortium, apologized to Blackmer and said the incident was a "missed opportunity" for dialogue. "Both sides need to listen to each other; it is not a one-way street."

The CMA position that aroused such ire is that, once cannabis becomes legal, there will no longer be a need for a separate regulatory system for medical cannabis. If patients can access cannabis legally, the medical system becomes redundant, according to the association.

Blackmer said the position is based on the lack of evidence for the efficacy of cannabis for most indications, and a lack of understanding of appropriate dosages and

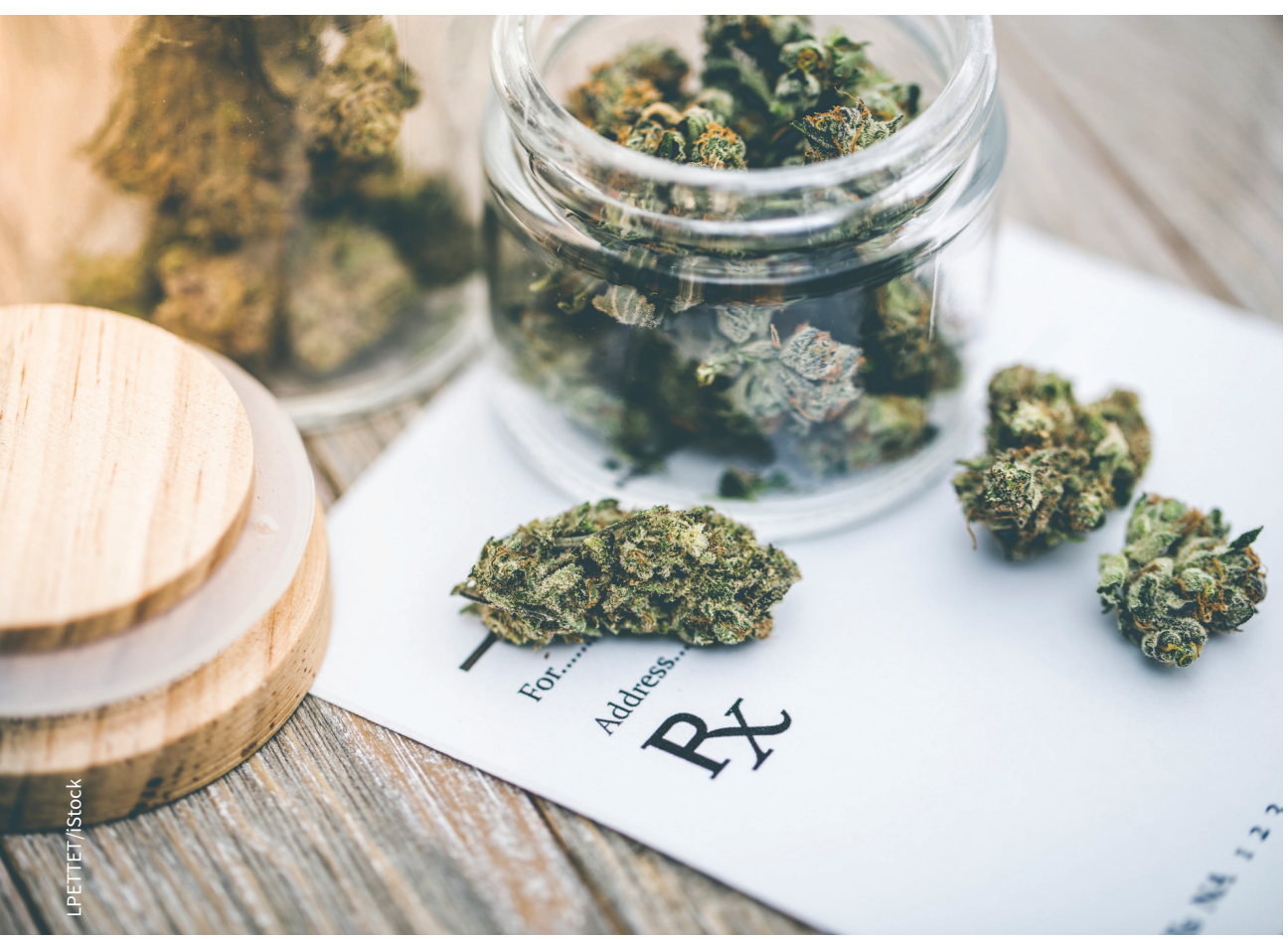

Some physicians say a medical stream for cannabis will still be necessary after the drug becomes legal, for reasons including patient access and insurance coverage. potential drug interactions. "Most physicians still feel uncomfortable providing prescriptions for cannabis as a medical product," he said. "They are being asked to treat it in a way they would never treat another substance. It would be anathema in any other area."

After legalization, patients who find that cannabis helps with their symptoms can access the drug through the legal system, said Blackmer. They can still consult with doctors or other health care professionals for advice, but will not require their permission or a prescription.

But those who support the medical use of cannabis fear that getting rid of a separate, regulated medical stream for the drug means patients who rely on it could lose access. Dr. Michael Verbora, medical director of Aleafia Health, a network of medical-cannabis clinics, said there are already issues with supply and demand for medical cannabis, which could be exacerbated by ending the medical stream. The strains favoured by recreational users will likely be different than those used by medicinal users, with higher levels of psychoactive tetrahydrocannabinol (THC) and less of the more benign cannabidiol (CBD). And without a prescription, it is unlikely health insurance plans will cover the cost of cannabis. "If we don't carve out a niche, patients could lose access, and might be forced to go back to using opioids," he said.

But perhaps the biggest issue, according to Verbora, is the stigma. "We want to normalize it as a medicine so that patients who might benefit, but are scared, feel safe." The CMA is "out of touch with what's happening on the front lines of medical cannabis," he said. 
Blackmer said the majority of CMA members do not believe there is sufficient evidence for the medicinal effects of cannabis, and do not support a separate medical stream. "Around seventy to eighty percent of our physicians say it is not part of their clinical practice," he said, cautioning that the figure is based on informal surveys. The CMA's policy is based on extensive consultations with members, as well as discussions among the CMA general council and board of directors. "I would say it was a fairly rigorous and extensive process," he said.
The CMA's stance differs from some other Canadian professional organizations in health care, however. Both the Canadian Nurses Association and the Canadian Pharmacists Association support a separate medical stream for cannabis. Karey Shuhendler, program lead on public policy for the nurses' association, said they see it as an issue of access and equity, and shares the concerns over the supply of medicinal strains and insurance coverage. In addition, she said, a medical stream is needed to ensure patients have clinical oversight. "If we remove that structure and have patients self-medicating through the recreational stream, it leaves them unsupported without medical advice."

Ware said most patients want to keep their doctors involved. "They are concerned that purchasing from a recreational outlet will not reflect the necessity of their medical needs."

The bill on this issue being debated in Parliament would maintain the separate medical stream for five years after legalization, before revisiting the issue.

Brian Owens, St. Stephen, NB 